\title{
Design and Implementation of a Novel Anti-theft Security Monitoring System for Advertising Lighting Lamps
}

\author{
Yiwang Wang ${ }^{1,}{ }^{*}$, Shukai Fan ${ }^{1}$, Peng Wang ${ }^{2}$, Sikui $\mathrm{Wu}^{1}$, Mengdi $\mathrm{Ni}^{1}$, \\ Lijuan Geng ${ }^{1}$,Chenhou Shi ${ }^{1}$ and Weiyuan Chen ${ }^{1}$ \\ 1 Suzhou Vocational University,Suzhou 215104,China \\ ${ }^{2}$ China Mobile Communications Group Shandong Co., Ltd.Jinan 250001, China \\ awyiwang@163.com
}

\begin{abstract}
Keywords: anti-theft security system;advertising lighting lamps;design and implementation; remote monitoring

Abstract. The advertising as a form of business promotion has more and more widely in different applications, and the lighting lamps is one of the key equipments in the entire outdoor advertising facilities. In order to improve advertising effectiveness and facilities security, especially for the outdoor advertising lighting applications in some remote areas, occasionally occur the advertising lamps stolen and damaged. A novel advertising lighting anti-thefts security system based on digital control technologies is designed and implementation in this paper. The designed system can achieve the real-time online status monitoring of advertising lighting lamps, once the abnormal situation the system can be issued on-site sound and light alarms and remote on-line notification, etc., which greatly improving the anti-theft security performance of outdoor advertising lighting.
\end{abstract}

\section{Introduction}

The outdoor advertising has features of high arrival rate, low cost, use and maintenance convenient. And the lighting is one of the key equipment in the entire outdoor advertising facilities. Because outdoor advertising is often in the wild or remote roadside, which occasionally occur stolen phenomenon, then advertising lighting can not normal operations ${ }^{[1-5]}$. Therefore, use of modern digital and control technologies to design intelligent anti-theft Security monitoring system for advertising lighting lamps.

A novel advertising lighting anti-thefts security system based on GPS and digital control technologies is designed and implementation in this paper. The system uses other digital control technologies, which can achieve outdoor lighting remote real-time online monitoring and alarm warning functions.

\section{The system design and working principle}

According to market needs analysis, the main functions of the system design requirements are: human PIR infrared monitor whether someone close to advertising lighting lamps, once someone close, it will send a signal to the controller level, then the controller to capture abnormal signals, voice alarm module will drive a warning sound, and LCD display warning information. If the system detects the lamp stolen, the controller will drive GPRS module send alarm/location information and message to the host computer monitoring software, then inform the staff as soon as possible.

The designed system consists of a terminal site controller and remote monitoring control software. The terminal site controller including MCU controller, lighting lamps status detection, security monitoring, position information and alarm module. The remote monitoring control software mainly realizes the lights work status and position display, alarm information. The entire system block diagram shown in Fig.1. 

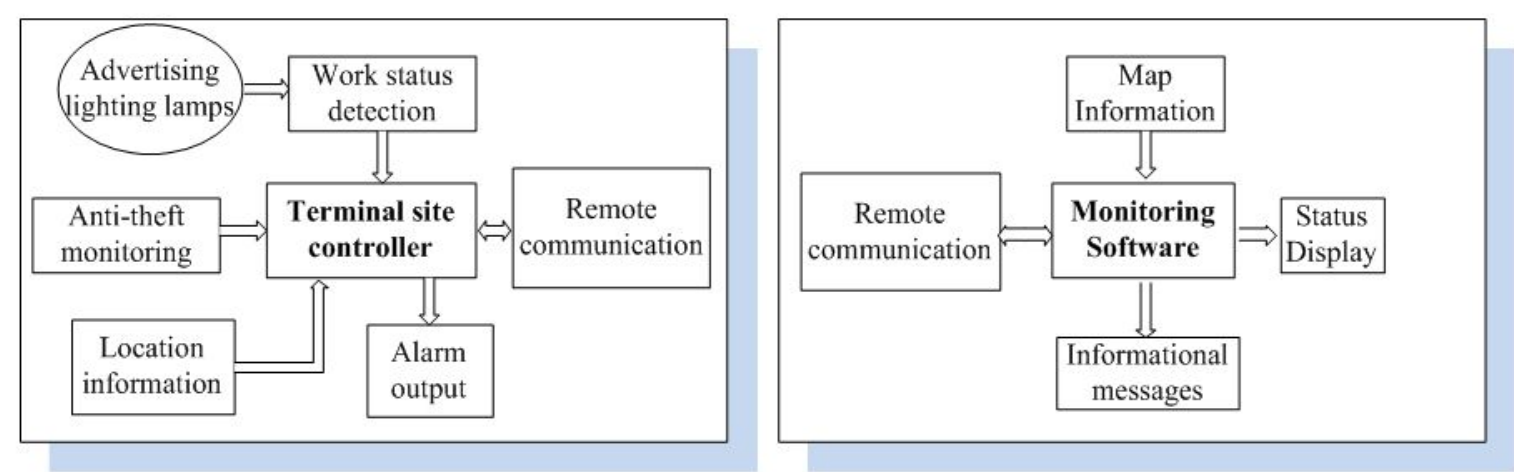

Fig.1 Block diagram of the system

\section{System hardware design}

The main controller. The system uses a STC15F2K60S2 ${ }^{[6]}$ microcontroller chip as main controller.The STC 15F2K60S2 microcontroller production is based on the new 8051 high-speed, high reliability, low power consumption and superior anti-jamming microcontroller.

GPRS and GPS modules.GPRS uses SIM900A R11.0 module, the and the GPS location information uses the BS-280GPS module ${ }^{[6-9]}$.

Detection sensor and voice alarm modules.Detection module including infrared body and lighting detection two modules, infrared detection module can detect whether the close to the lamps. Lighting detection module can detect whether stolen. Voice alarm module can achieve sound alarm output, they with microcontroller interface circuits shown in Fig.2.
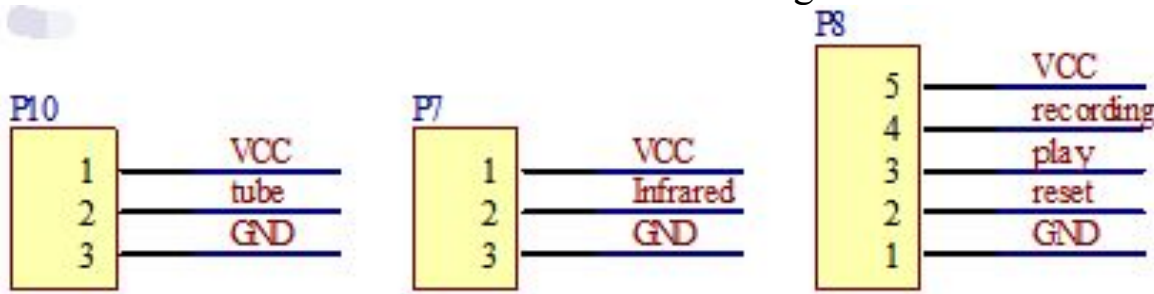

Fig. 2 Detection sensor and voice alarm modules interface circuits

Display circuit and control power supply circuit. The controller uses LCD12864 as system information display ${ }^{[9]}$. Because the instantaneous power of GPRS module when transmitting signals is larger, in order to prevent instantaneous large current, so the system use two LM2596 chips as power supply. Power supply sources of electricity supply can be powered by solar and other clean power supply mode ${ }^{[10]}$.

\section{System software design}

The implemented functions of whole controller system software are: switch semaphore acquisition, data processing and sending serial port to receive instruction, display LCD driver. Switch semaphore acquisition is mainly used for signal detection and location of the body infrared switch, serial port to receive GPS data processing, send commands to drive the GPRS module and send SMS alarm messages, I / O port level switching drive the alarm module. Software flow chart shown in Fig.3 


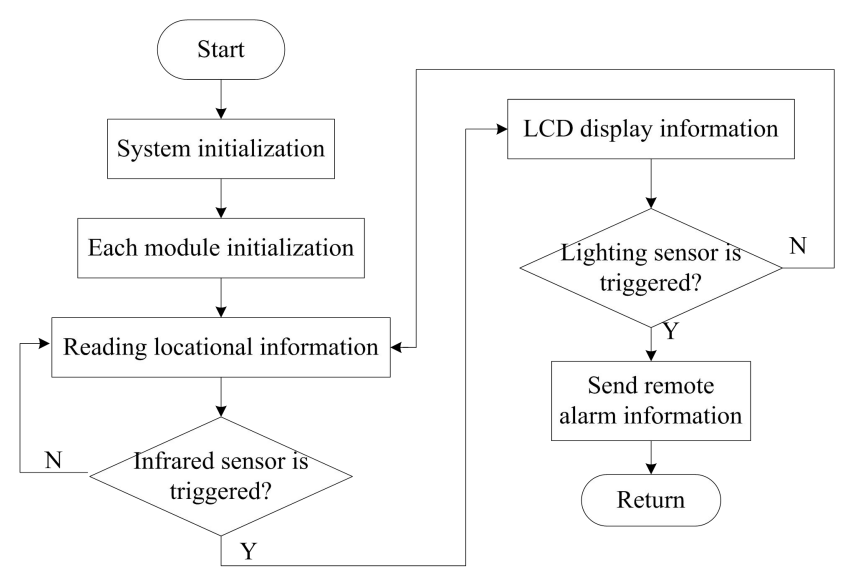

Fig.3 The controller software flow chart

PC monitoring software using VB design, the main functions include a map display, Communication settings, send command and lamps status diaplays. PC monitoring software composition diagram as shown in Fig.4.

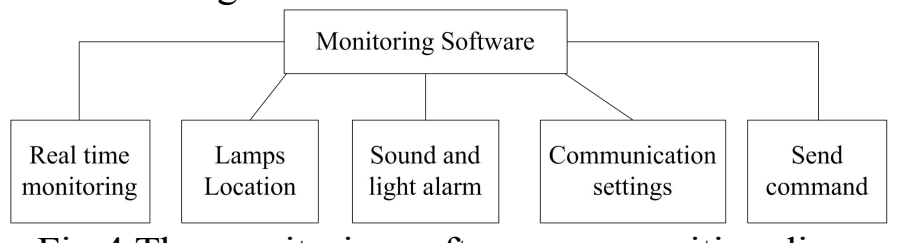

Fig.4 The monitoring software composition diagram

\section{System implementation and testing experiment}

Design and development of a prototype system, and test testing experiment. The developed prototype is shown in Fig.5.

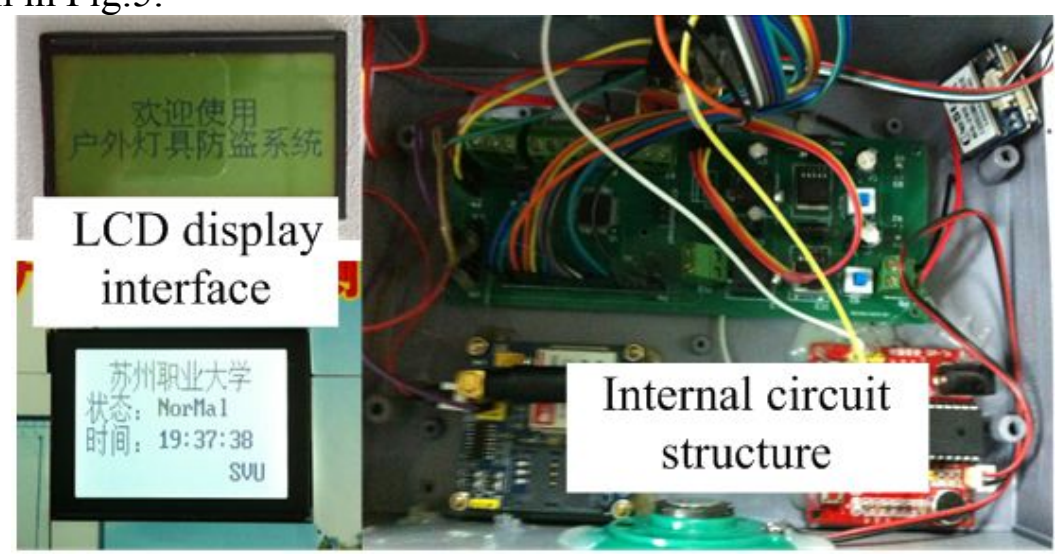

Fig. 5 The system prototype

Test experiment picture as shown in Fig.6

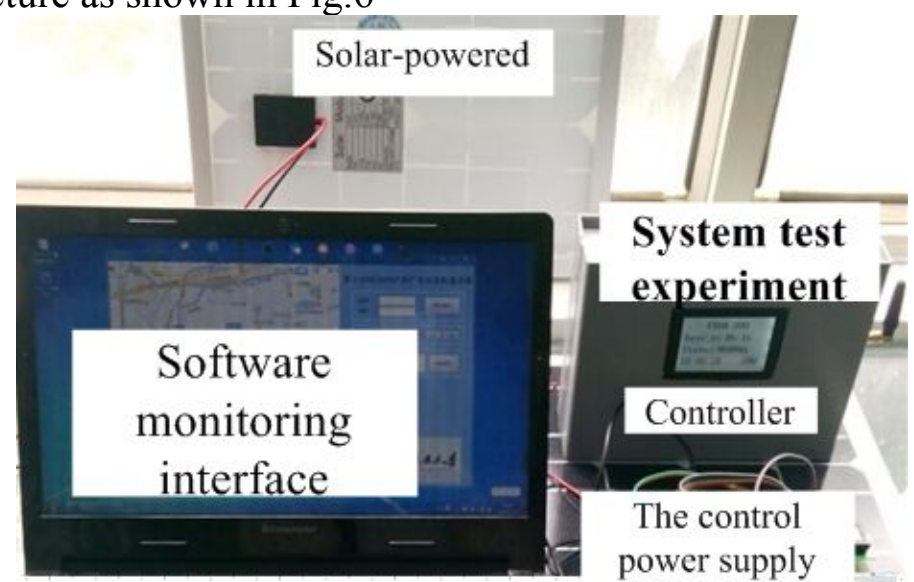

Fig.6 System test experiment 


\section{Summary}

According to the modern monitoring requirements of advertising lighting lamps anti-theft security, design and development of a novel intelligent advertising lighting anti-theft system especially for the outdoor advertising lighting applications in some remote areas, the designed system can be achieved on-line monitoring of advertising lighting, burglar alarm, positioning monitoring and etc.. The system through the designed prototype experimental verification is feasible, which indicates that the system can meet the needs of advertising lighting lamps monitoring and management of applications in some applications.

\section{Acknowledgements}

The research work was partly supported by the Scientific Research Achievement Innovation Foundation \& Teaching Reform Project of Suzhou Vocational University, Qing Lan Project, Science and Technology Project of Jiangsu Province Construction System.

\section{References}

[1] Qin Xin,Wang Aiying. Research on the Urban Outdoor Advertisements Board Lighting. China Illuminating Engineering Journal,2009,20(1):59-63.

[2] FANG Qing-li, PENG Mai-fu. The Relationship between the CIS-based Outdoor Advertising and City Image Construction. PACKAGING ENGINEERING.2015,36(8):116-119

[3] WANG Yan. ZHANG Rui. Orchard Anti-theft Alarm System Based on ZigBee Technique. Hubei Agricultural Sciences,2009,48(4):971-973.

[4] Bu Feng, Li Chuanjiang, Li Huan, Lu Yongnan. Design and Implementation of Vehicle Remote Monitoring System Based on GPS/GPRS. Computer Measurement \& Control, 2014 .22(1):79-81.

[5] Sun Zhaoxiang,Liu Jun,Hu Hao. Design of Vehicle Monitoring Terminal System Based on GPS and GPRS. JOURNAL OF HUBEI ENGINEERING UNIVERSITY,2015,35(3):32-35.

[6] Information on http://www. stcmcu.com/

[7]Deng Xiaolei , Li Minzan, Wu Jia, et al. Development of mobile soil moisture monitoring system integrated with GPRS, GPS and ZigBee. Transactions of the Chinese Society of Agricultural Engineering (Transactions of the CSAE), 2012, 28(9): 130-135.

[8] Jiang Dingguo, Xu Baoguo, Wang Mingsheng. Design of greenhouse evironment remote monitoring system based on GPRS. Guangdong Agricultural Sciences, 2011(13): 160-162.

[9] Information on http://wenku.baidu.com

[10] Yiwang Wang, Bo Zhang, Houchen Shi, Shuai Zhang. Design of a Photovoltaic DC Power Supply System for Outdoor Controller Equipment.Journal of Applied Science and Engineering Innovation, Vol.2 No.10 2015, pp. 407-409

[11] XIE Bi-feng, ZHANG Ju. Design of household security control system based on GPRS network. JOURNAL OF ZHEJIANG UNIVERSITY OF TECHNOLOGY,2011,39(2):181-186

[12] CHEN Lin, YANG Guo-hua, ZHOU Shi-wen, DING Xiao-hua. Monitoring system of cross structure street lights based on Zigbee and GPRS. Chinese Journal of Power Sources 2015,32(9):416-418 